\title{
Presentación
}

https://doi.org/10.33996/revistalex.v4i12.72

MSc. Karen Abigail Sequeiros Olivares

Editora de la Revista Lex

Para la revista Lex Vol. $4 \mathrm{~N}^{\circ} 12$ (Abril-junio 2021) es un honor continuar abriendo espacios propios de discusiones que exige la investigación jurídica. Las problemáticas fomentan la búsqueda de soluciones, explicaciones y cuestionamientos que posibilitan comprender mejor las ciencias del Derecho. De esta manera, Lex contribuye con la difusión de nuevos enfoques en el orden social, en especial los vínculos entre particulares y el Estado.

Conviene destacar que el estudio de las ciencias jurídicas permite entender el rol que juega el mismo en la percepción activa y participativa ante la pluralidad de problemas que se suman por los cambios drásticos que se viven actualmente.

Así, este número se detiene en la valoración que realizan cada uno de los autores sobre el desarrollo de una disciplina como la jurídica, la cual requiere de metodologías y discusiones para propiciar nuevos debates. Cuatro investigaciones conforman el corpus de la presente edición.

Se inicia con el artículo "Rehabilitación integral de las personas sentenciadas penalmente para reinsertarlas en la sociedad" de los autores Maicol Alejandro Oleas Plaza y Edison Manuel Pozo Calderón, quienes explican que resulta insuficiente que las autoridades penitenciarias se limiten a tratar a los reclusos de manera humana y decente, adicionalmente deberían proporcionar a los internos, bajo su custodia, oportunidades de crecimiento. No obstante, argumentan los autores que esta acción requiere considerables aptitudes y un alto nivel de compromiso.

El segundo estudio pertenece a la investigadora Jimena Portugal Dorado, la cual analiza la identificación de la naturaleza de la figura jurídica en los delitos de corrupción incorporada en la legislación boliviana. Se develan elementos constitutivos de un contexto social en cuanto a que el Estado quiere intensificar el problema de la persecución respecto al tema de corrupción. Pero toda esa intensidad también puede terminar generando una afectación a los derechos de los investigados. Detallando que la normativa de la Constitución Política autoriza la aplicación retroactiva de la ley penal para los casos de corrupción de funcionarios.

Flavio Abastoflor Dupleich plantea el diseño y la incorporación de un parágrafo quinto en el artículo 13 Título II, de la Constitución Política del Estado que establezca la imprescriptibilidad de vulneraciones a derechos y garantías constitucionales, así como la retroactividad. 
MSc. Karen Abigail Sequeiros Olivares

\section{Directora de Revista}

Por último, se expone un artículo de revisión de la autora Fabiola Beatriz Puch Tórrez donde se analiza críticamente diferentes Sentencias Constitucionales que puntualizan el principio de subsidiariedad excepcional de la Acción de Libertad para tutelar derechos sin perjuicio que exista otro medio o recurso legal.

Se enfatiza pues que cada uno de los autores del presente número invita con sus estudios a repensar la trascendencia de la investigación jurídica en la sociedad actual.

Los miembros del Equipo Editorial de Lex invitan a sus lectores a publicar sus investigaciones en los próximos números. 